\section{Apoptose em Tiroidopatias Hiperplásicas e Neoplásicas}

\section{RESUMO}

A apoptose é um processo de morte celular que ocorre geralmente após a fragmentação progressiva do DNA e parece ser importante em tecidos normais e neoplásicos. Pouco é conhecido sobre a ocorrência da apoptose nas doenças da tiróide. A finalidade deste estudo é investigar um possivel papel da apoptose no crescimento do carcinoma bem diferenciado de tiróide, usando um ensaio com nucleotidil transferase in situ (ENTIS), o qual detecta a fragmentação do DNA, para determinar a freqüência da apoptose no bócio colóide (BC), adenoma folicular (AF), carcinoma folicular (CF) e carcinoma papilar (CP). Os tecidos de BC $(n=3), \operatorname{AF}(n=2), C F(n=4)$ e CP (n=3) foram obtidos de ressecção cirúrgica em 12 pacientes. As células apoptóticas positivas (CAP) dentro do folículo tiroidiano e tecido neoplásico foram contadas em áreas de $1 \mathrm{~cm}^{2}$. $O$ teste $T$ foi utilizado para testar a significância estatística. $O$ número de CAPs fol significantemente maior $(p<0,0001)$ nos $B C$ e AF $(24,4 \pm 8,2$ CAP $\left./ \mathrm{cm}^{2}\right)$ comparado com CF e CP $\left(1,33 \pm 0,82 \mathrm{CAP} / \mathrm{cm}^{2}\right)$. Nenhuma diferença significativa foi vista no número de CAPs entre BC e AF e entre CF e CP. A apoptose pode desempenhar um importante papel na progressão do carcinoma bem diferenciado de tiróide, visto que no presente estudo o índice apoptótico foi muito baixo nessas neoplasias. A apoptose, diferentemente da necrose, é um processo ativo que poderia ser inibido ou induzido o que, neste caso, seria interessante para a terapêutica. (Arq Bras Endocrinol Metab 2000;44/2: 153-6)

Unitermos: Apoptose; Tiróide: Hiperplasia; Neoplasia; Tiroldopatias.

\section{artigo original}

\author{
Marcus A, Lima \\ Jacqueline F. Rios \\ Lília B. Oliveira \\ Danielle P.C. Rita \\ Marta E.A. Araújo \\ Maria F. Borges
}

\title{
ABSTRACT
}

Apoptosis is a process by which cell death occurs after progressive fragmentation of DNA and that seems to be important in normal and neoplastic tissues. Little is known about the role of apoptosis in the thyroid disease. The aim of this study is to investigate a possible role of apoptosis in growth of well-differentiated carcinoma of thyroid using an in situ nucleotidyl transferase assay (ISNTA), which detects DNA fragmentation, to determine the frequency of apoptosis in nodular goiter (NG), follicular adenoma (FA), follicular carcinoma (FC) and papillary carcinoma (PC). Surgical resection specimens were obtained from 12 patients including $N G(n=3), F A(n=2), F C(n=4)$ and $P C(n=3)$. Positive apoptotic cells (PAC) within the thyroid follicle and neoplastic tissue were counted per section of $1 \mathrm{~cm}^{2}$. Unpaired t test was utilized to test for statistical significance. The number of PACs were significantly greater $(p<0.0001)$ in NG and FA $\left(24.4 \pm 8.2 \mathrm{PAC} / \mathrm{cm}^{2}\right)$ than in $\mathrm{FC}$ and $\mathrm{PC}\left(1.33 \pm 0.82 \mathrm{PAC} / \mathrm{cm}^{2}\right)$. No significant difference was found in the number of PACs between NG and FA and between FC and PC. Apoptosis may play an important role in progression of well-differentiated carcinoma of thyroid gland. This study showed that inhibition of the apoptosis might be implicated in development of the carcinomas of thyroid, considering that the apoptotic index was low in these tumors. Apoptosis, differently from the necrosis, is an active process that could be inhibited or induced, which might have

Recebido em 01/03/1999

Revisado em 28/06/1999 e 21/10/1999

Aceito em 20/12/1999 
interesting implications for therapy. (Arq Bras Endocrinol Metab 2000;44/2: 153-6)

Keywords: Apoptosis; Thyroid; Hyperplasia; Neoplasia; Thyroid disease.

A morte celular programada foi observada há 40 anos e, inicialmente, foi chamada de necrose de redução. Este tipo de morte celular é complementar à mitose na regulação da proliferação celular animal, e, em virtude do seu importante papel cinético, este fenômeno recebeu, em 1971, o nome de "Apoptosis" (1). A apoptose é um tipo de morte celular que se diferencia da necrose por fatores bioquímicos e ultra-estruturais e é caracterizada pela redução no tamanho da célula, condensação da cromatina, geralmente com fragmentação do núcleo e do DNA e perda da integridade da membrana plasmática, podendo acontecer em processos normais e patológicos (2). Ocorre nos sistemas imune $(2,3)$, nervoso (4) e anormalidades nos seus níveis desencadeiam doenças: a sua inibição gera hiperplasia ou auto-imunidade, enquanto a exacerbação, ocasiona doenças degenerativas (5).

A transformação tecidual reflete um desequilíbrio entre a proliferação e a morte celular. Sendo assim, a perda da apoptose, por si só, é relevante na carcinogênese e a sua perfeita compreensão, bem como a de seus mecanismos reguladores, permitiria o estabelecimento de uma terapêutica tumoral mais eficiente $(6,7)$.

Tem sido observado que os carcinomas bem diferenciados de tiróide, papilífero e folicular, mostram taxas de crescimento extremamente baixas, em relação a carcinoma de mesmo grau histológico que ocorre em outros órgãos, tais como mama, pulmão, cólon e estômago $(8,9)$. Questiona-se o modo pelo qual estes tumores de tiróide crescem, e já foi proposta a hipótese de que a inibição da apoptose estivesse implicada no desenvolvimento destas neoplasias; entretanto, os estudos sobre a expressão de bcl-2, proteína inibidora de apoptose, em neoplasias de tiróide (10) não mostraram diferenças significativas em comparação com tecidos tiroidianos não-neoplásicos $\mathrm{e}$ normais $(11,12)$. Estes achados sugerem que bcl-2 não deve ter um papel importante na patologia dessas lesões.

Em vista do exposto, pretende-se buscar outros dados que auxiliem no esclarecimento do(s) mecanismo(s) de progressão das neoplasias malignas bem diferenciadas de tiróide, comparando a apoptose, que ocorre nestas neoplasias, com aquela detectada nas tiroidopatias benignas.

\section{MATERIAL E MÉTODOS}

\section{Seleção de casos}

Foram examinadas 3 tiróides hiperplásicas (bócios colóides - BC) e 9 neoplásicas [ 2 adenomas foliculares $(\mathrm{AF}), 4$ carcinomas foliculares $(\mathrm{CF})$ e 3 carcinomas papilíferos (CP)] obtidas de tiroidectomias.

Os diagnósticos das tiroidopatias não neoplásicas fundamentaram-se na morfologia histológica clássica e os diagnósticos das neoplasias foram feitos de acordo com os critérios histológicos de Hedinger et al. (13) e modificados por Rosai et al. (14).

\section{Ética médica}

O estudo está de acordo com a Declaração de Helsinki de 1975, revista em 1983.

\section{Marcação de DNA em células apoptóticas}

Com o objetivo de detectar células apoptóticas, utilizou-se a marcação in situ da extremidade 3' de fragmentos de DNA originados por endonucleases associadas à apoptose. A marcação da extremidade 3' do DNA foi realizada utilizando o marcador para detecção da apoptose in situ ApopTag (Oncor, Gaithesburg, MD, USA), como previamente descrito (15).

\section{Técnica do Apoptag}

Os tecidos tiroidianos obtidos pela tiroidectomia foram fixados em formalina, embebidos em parafina e cortados a uma espessura de $4 \mu \mathrm{m}$. Foram amostrados, em média, seis cortes de tecido por glândula. Os cortes foram desparafinizados $\mathrm{em}$ xilol por cinco minutos, lavados em dois banhos de cinco minutos de etanol absoluto, hidratados em álcool a $95 \%$ e $70 \%$ por três minutos e colocados em solução tampão tris (TBS) $0,05 \mathrm{M}$ pH7, 5 por cinco minutos. Posteriormente, os espécimes foram incubados em proteinase $\mathrm{k}$ a $200 \mu \mathrm{g} / \mathrm{ml}$ durante 40 minutos a $25^{\circ} \mathrm{C}$. Em seguida, foram lavados quatro vezes em água destilada, incubados em $\mathrm{H}_{2} \mathrm{O}_{2}$ a $2 \%$, por cinco minutos, a $25^{\circ} \mathrm{C}$ e colocados em solução de tampão de salina fosfato (PBS) $0,1 \mathrm{M} \mathrm{pH} \mathrm{7,4}$ por duas vezes de cinco minutos. Posteriormente, as lâminas foram incubadas em tampão de equilíbrio por 20 minutos; em seguida, foi colocada solução da enzima deoxinucleotidil transferase terminal ( $\mathrm{TdT})$ sobre as lâminas que foram recobertas com plástico transparente, para melhor distensão da solução. Após incubação de uma hora, a $37^{\circ} \mathrm{C}$, as lâminas foram lavadas com tampão de lavagem e de parada súbita da reação por dez minutos a $25^{\circ} \mathrm{C}$. Os cortes foram passados três vezes de quinze minutos por solução de PBS e depois incubados em $55 \mu$ de anti- 
digoxigenin peroxidase (S7101-5) durante 30 minutos a $25^{\circ} \mathrm{C}$. Posteriormente, as lâminas foram lavadas quatro vezes de cinco minutos com PBS e colocadas em $125 \mathrm{ml}$ de solução de hidrocloreto de diaminobenzidina por três a seis minutos e depois lavadas em água destilada por três vezes de um minuto. Em seguida, os cortes foram contracorados com verde de metila a $0,05 \%$ durante dez minutos, lavados em água destilada, passados três vezes de 30 segundos por butanol a $100 \%$ e montados com xilol e entelan.

Finalmente, fez-se a análise das lâminas por três observadores relatando o índice apoptótico.

\section{Índice Apoptótico}

As células foram definidas como apoptóticas se toda a área nuclear da célula fosse positiva e houvesse corpos apoptóticos como corpos globulares pequenos, isoladamente ou em grupos, positivos nos citoplasmas das células.

O índice apoptótico foi definido como a soma das células apoptóticas e que continham corpos apoptóticos, o que reflete o número total de eventos apoptóticos em uma determinada área de $1 \mathrm{~cm}^{2}$. Foram analisados cinco campos de $1 \mathrm{~cm}^{2}$ por glândula. Foi também contado o número total de células para medir a densidade celular.

\section{ANÁLISE ESTATÍSTICA}

$\mathrm{Na}$ comparação entre tiroidopatias benignas (BC+AF) e malignas $(\mathrm{CF}+\mathrm{CP})$, utilizou-se o teste $\mathrm{T}$. Considerou-se o nível de significância de 5\%.

\section{RESULTADOS}

\section{Expressão de apoptose em tiroidopatias benignas}

Foram analisadas 3 tiróides hiperplásicas, com bócio colóide, e a expressão de apoptose ocorreu nas 3 tiróides estudadas, variando de 18 a 25 células $/ \mathrm{cm}^{2}$, e nos 2 casos de adenomas foliculares a positividade variou de 18 a 38 células $/ \mathrm{cm}^{2}$, com densidade celular de 12000 a 15000 células/campo.

\section{Expressão de apoptose em tiroidopatias malignas}

Em relação aos carcinomas papilares, havia apoptose em 2 dos 3 casos analisados, sendo a expressão rara e observada apenas em 1 a 2 células $/ \mathrm{cm}^{2}$, com densidade celular de 12000 a 15000 células foliculares/campo.

Da mesma forma, nos carcinomas foliculares, a expressão foi escassa e ocorreu em 1 a 2 células $/ \mathrm{cm}^{2}$.

A comparação entre as tiroidopatias benignas e malignas mostrou diferença extremamente significativa, sendo $\mathrm{P}<0,0001$. Os resultados estão expressos na Tabela 1.
Tabela 1 - Índice apoptótico em tiroidopatias benignas e malignas (células apoptóticas $/ \mathrm{cm}^{2}$ ).

Índice apoptótico em 13.500 células $/ \mathrm{cm}^{2}$

\begin{tabular}{lcccc}
\cline { 5 - 5 } Diagnóstico & $N$ & Média & Desvio padrão & Variação \\
\hline Adenoma folicular & 2 & 28 & 14,1 & $18-38$ \\
Bócio nodular & 3 & 22 & 3,6 & $18-35$ \\
Carcinoma folicular & 4 & 1,3 & 0,5 & $01-02$ \\
Carcinoma papilar & 3 & 1,0 & 1,0 & $00-02$ \\
\hline
\end{tabular}

\section{DISCUSSÃO}

Nós pretendemos buscar dados que auxiliem no esclarecimento do(s) mecanismo(s) de progressão das neoplasias malignas bem diferenciadas de tiróide, comparando a apoptose, que ocorre nestas neoplasias, com aquelas detectadas nas tiroidopatias benignas.

Nos adenomas foliculares e hiperplasias da tiróide, a expressão de apoptose foi elevada, e isto sugere que a morte celular programada ocorre, nestes casos, de modo mais intenso, aumentando a homeostase tissular, uma vez que ambas as doenças são benignas. Não há relatos na literatura sobre os índices apoptóticos em tiróides normais. Porém, sabe-se que a apoptose tem sido observada, ocasionalmente, em secções histológicas de tiróide normal (16), e este processo é anormalmente acelerado durante as fases de maior atividade da Tiroidite de Hashimoto (17).

Uma molécula chamada Fas, encontrada na superfície celular, é uma das chaves no processo de morte celular programada (18). Células tiroidianas normais não sofrem apoptose porque expressam quantidade insignificante de Fas (18-20).

Em relação aos 7 carcinomas bem diferenciados de tiróide, folicular e papilífero, ambos apresentaram número muito baixo de células apoptóticas, havendo uma diferença de expressão de apoptose entre as tiroidopatias benignas e malignas extremamente significante.

A comparação da apoptose entre as tiroidopatias benignas e malignas sugere que a inibição da apoptose deve estar implicada no desenvolvimento dos carcinomas bem diferenciados de tiróide, visto que o índice apoptótico foi muito baixo nestas neoplasias e a diminuição da apoptose, por si só, é relevante na carcinogênese (15). Isso é importante porque a apoptose, diferentemente da necrose, é um processo ativo que, a princípio, pode ser inibido ou induzido, o que, nestes casos, seria interessante para a terapêutica (21).

Quanto à apoptose relacionada à carcinogênese, há relatos de que alterações genéticas cumulativas em oncogenes e genes supressores de tumor estão envolvi- 
das na gênese tumoral. O comportamento desses tumores é dependente da cooperação e antagonismo de vários genes associados também envolvidos na apoptose como p53, bcl-2, c-myc, Fas-Apo-1, MDR1, MDR-2, entre outros (15). As concentrações relativas das várias proteínas codificadas por estes genes determinam o destino da célula (22).

O presente estudo mostra que a falta de predisposição dos carcinomas bem diferenciados de tiróide em sofrer apoptose poderia explicar a irresponsividade destas neoplasias à radio e quimioterapia. A tendência em sofrer apoptose está provavelmente na dependência da relação das proteínas bax e bcl-2. Em trabalho anterior (12), já demonstramos uma elevada incidência da imunopositividade para a proteína bcl-2 em carcinomas bem diferenciados de tiróide e estas alterações em bcl-2 aumentam a sobrevivência celular, permitindo a expansão e evolução oncogênica.

A carcinogênese é um processo cvolutivo complexo, facilitado por aumento da instabilidade genética. Consequentemente, o comportamento dos tumores é dependente da cooperação e antagonismo dos vários genes associados. Um conhecimento mais profundo a respeito da interação destes genes na regulação da apoptose promoverá uma abordagem mais eficaz e racional das neoplasias humanas (15).

\section{REFERÊNCIAS}

1. Kerr JF, Wyllie AH, Currie AR. Apoptosis: a basic biological phenomenon with wide ranking implications in tissue kinetics. Br J Cancer 1972;26:239-57.

2. Schulze-Osthoff $K$, Walczak $H$, Droge $W$, Krammer $P H$. Cell nucleus and DNA fragmentation are not required for apoptosis. J Cell Biol 1994;127:15-20.

3. Chandler D, EI-Naggar AK, Brisbay S, Redline RW. McDonnell TJ. Apoptosis and expression of the bcl-2 proto-oncogene in the fetal and adult human kidney: evidence for the contribution of bcl-2 expression to renal carcinogenesis. Hum Pathol 1994:25:789-96.

4. Robertson LE, Plunkett W. Apoptotic cell death in chronic lymphocytic leukemia. Leuk Lymphoma 1993; 11:71-4.

5. Meyn RE, Milas L, Stephen C. Programmed cell death in normal development and disease. Cancer Bull 1994:46:120-4

6. Di Vinci A, Geido E, Infusini E, Giaretti W. Neuroblastoma cell apoptosis induced by the synthetic retinoid $n$-(4hydroxyphenyl) retinamide. Int J Cancer 1994;59:422-6.

7. Schulte-Hermann R, Bursch W, Grasl-Kraupp B, Török L, Ellinger A, Müllauer $L$. Role of active cell death (apoptosis) in multi-stage carcinogenesis. Toxicol Lett 1995:82/83: 143-8.

8. Katoh R, Bray CE, Suzuki K, Komiyama A, Hemmi A, Kawaoi, et al. Growth activity in hyperplastic and neoplastic human thyroid determined by an immunohisto- chemical stainning procedure using monoclonal antibody MIB-1. Hum Pathol 1995:26:139-46.

9. Lima MA, Gontijo VA, Schmitt FCL. CD26 (dipeptidyl aminopeptidase IV) expression in normal and disease human thyroid glands. Endocr Pathol 1998:9:43-52.

10. Manetto V, Lorenzini R, Cordon-Cardo C, Krajewski S, Rosai $\mathrm{J}$, Reed $\mathrm{JC}$, et al. $\mathrm{BCl}-2$ and $\mathrm{Bax}$ expression in thyroid tumors. An immunohistochemical and western blot analysis. Virchows Arch 1997:430: 125-30.

11. Branet $F$, Caron $P$, Camallières $M$, Selves $J$, Brousset $P$ $\mathrm{BCl}-2$ proto-oncogene expression in neoplastic and nonneoplastic thyroid tissue. Bull Cancer 1996:83:213-7.

12. Lima MA, Gontijo VA. Expressão da proteína bcl-2 em tiróides normais e tiroidopatias. Arq Bras Endocrinol Metab 1998:42(3):229-34.

13. Hedinger C, Williams ED, Sobin LH. Histological Typing of Thyroid Tumors. WHO International Histological Classification of Tumors. 2nd ed. Berlin: Springer-Verlag, 1998.

14. Rosai J, Carcangiu ML, De Lellis RA. Atlas of Tumor Pathology. Tumors of the thyroid gland. Washington: Armed Institute of Pathology, fasc. 5, 1992.

15. Delfino AB, Barreto EC, Silva Jr ET, Mendonça RG, Ornellas $\mathrm{MH}$. O envolvimento de genes e proteínas na regulação da apoptose - Carcinogênese. Rev Bras Cancerol 1997:43(3):173-86

16. Dremier S, Golstein J, Mosselmans R, Dumont JE, Galand $\mathrm{P}$, Robaye B. Apoptosis in dog thyroid cells. Biochem Biophys Res Comum 1994;200(1):52-8.

17. Kotani T, Aratake Y. Hirai K, Fukazawa Y, Sato H, Ohtaki S. Apoptosis in thyroid tissue from patients with Hashimoto's Thyroiditis. Autoimunity 1995:20(4):231-6.

18. Williams N. Thyroid Disease: A case of cell suicide? Science 1997:275:926.

19. Giordano C, Stassi $G$, De Maria R, Todaro M, Richiusa P, Papoff $G$, et al. Potential involvement of Fas and its ligand in the pathogenesis of Hashimoto's Thyroiditis. Science 1997:275:960-3.

20. Baker JR Jr. Dying (apoptosing?) for a consensus on the Fas death pathway in the thyroid. J Clin Endocrinol Metab 1999;84(8):2593-5.

21. Saraste A, Pulkki K, Kallajoki M, Henriksen K, Parvinen M, Voipio-Pulkki LM. Apoptosis in human acute myocardial infarction. Circulation 1997:95(2):320-3.

22. Kernohan NM, Cox LS. Regulation of apoptosis by bcl-2 and its related proteins: immunochemical challenges and therapeutic implications. J Pathol 1996;179:1-3.

\section{Endereço para correspondência:}

Marcus Aurelho de Lima

Disciplina de Endocrinologia - Hospital Escola

Faculdade de Medicina do Triângulo Mineiro

Rua Getúlio Guaritá, 130

38025-440 Uberaba, MG

Fax: (034) 312-6640

e-mail: lima@mednet.com.br 